\title{
Photoaffinity Labeling of Respiratory Complex I in Bovine Heart Submitochondrial Particles by Photoreactive $\left[{ }^{125} \mid\right]$ amilorides \\ Masatoshi Murai and Hideto Miyoshi*
}

\author{
Division of Applied Life Sciences, Graduate School of Agriculture, Kyoto University, Sakyo-ku, Kyoto \\ 606-8502, Japan \\ *For correspondence: miyoshi@kais.kyoto-u.ac.jp
}

\begin{abstract}
[Abstract] The architecture of quinone/inhibitor-access channel in proton-translocating NADH-quinone oxidoreductase (respiratory complex I) was modeled by X-ray crystallography and cryo-EM, however, it remains debatable whether the channel model reflects the physiologically relevant state present throughout the catalytic cycle. Using photoreactive [125|]amilorides, we demonstrated that amiloride-type inhibitors bind to the interfacial region of multiple subunits (49-kDa, ND1, PSST, and 39-kDa subunits), which is difficult to reconcile with the current channel model. This report describes the procedures for photoaffinity labeling of bovine submitochondrial particles by photoreactive [125|]amilorides. The protocol could be widely applicable for the characterization of various biologically active compounds, whose target protein remains to be identified or characterized.
\end{abstract}

Keywords: Photoaffinity labeling, Respiratory complex I, Amilorides, Enzyme inhibitor, Mitochondria, Bioenergetics, NADH-quinone oxidoreductase, Chemical biology

[Background] Proton-translocating NADH-quinone oxidoreductase (respiratory complex I) is a multisubunit membrane protein complex, which catalyzes the initial step of mitochondrial/bacterial electron transport chains (Hirst, 2013). The recent progress in X-ray crystallography and cryo-EM enabled modeling the entire structure of complex $\mathrm{I}$. The structural studies proposed the quinone/inhibitor-access channel model to explain how quinone/inhibitor bind to the enzyme (Sazanov, 2015; Wirth et al., 2016). However, since there is currently no structural data of complex I with bound-quinone or inhibitor, it remains debatable whether the channel model reflects the physiologically relevant state present throughout the catalytic cycle.

Photoaffinity labeling technique, which uses a synthetic ligand that possesses photoreactive group such as diazirine and phenyl-azido, is the most commonly used method of affinity-based protein modification (Hatanaka and Sadakane, 2002). It provides a powerful means of investigating interactions between biologically active compounds and the proteins of interest. Recently, to get insights into the structure of quinone/inhibitor-binding site in mitochondrial complex I, we carried out photoaffinity labeling using photoreactive [125I] amilorides ([125I]PRA3, [ $\left.{ }^{125}\right]$ PRA4, [ $\left.{ }^{125}\right]$ PRA5, and [125I]PRA6) with bovine heart submitochondrial particles (SMPs) (Uno et al., 2019). The radioisotope (125I) was used as a tracer, which enables the experiment with the lowest concentrations of ligands (1-10 nM). These concentrations are approximately two orders of magnitude lower than those of alkyne-tagged amilorides (PRA1 and PRA2, Murai et al., 2015), which can be conjugated with biotin or fluorophores via $\mathrm{Cu}^{+}$-catalyzed click chemistry 
(Wang et al., 2003) after cross-linking reaction. This advantage may minimize the possibility of nonspecific labeling, which is a primary cause of false-positive results.

We herein describe the detailed procedures of the photoaffinity labeling of complex I in bovine SMPS by [ ${ }^{125}$ ] $P R A 5$ as an example (Figure 1 ), which includes 1 ) preparation of ${ }^{125}$-tagged photoreactive ligand, 2) cross-linking of bovine SMPs by the ligand, and 3) identification of the labeled protein(s).
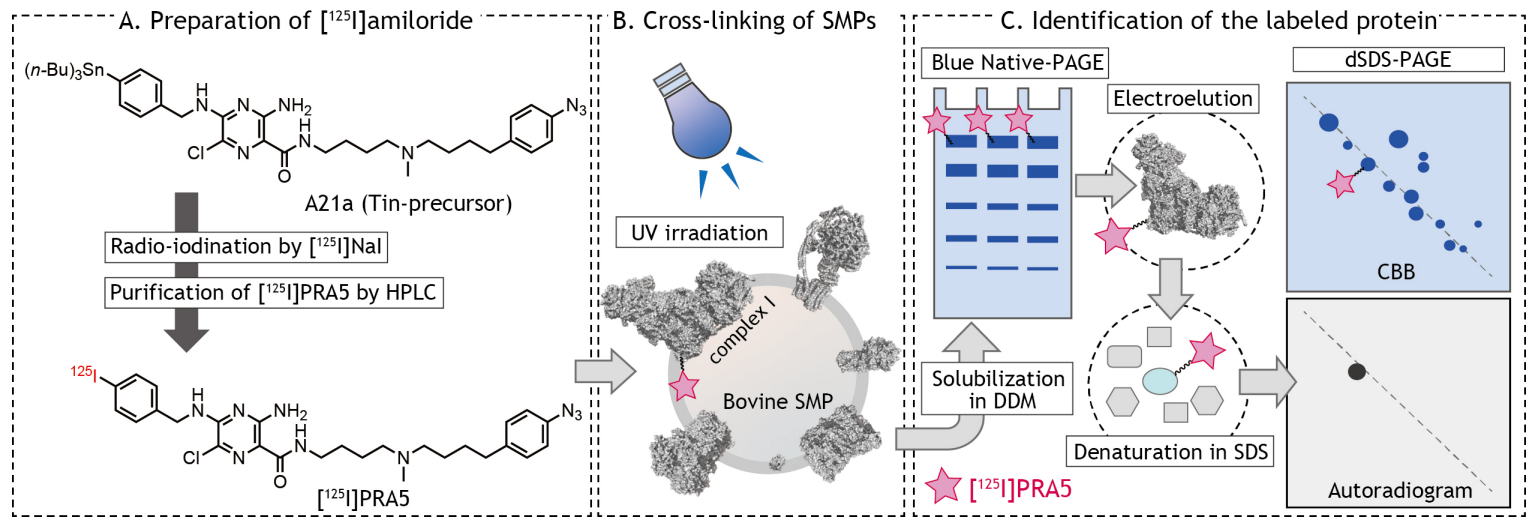

Figure 1. Schematic presentation of photoaffinity labeling of bovine heart SMPs by [125I]amilorides

\section{Materials and Reagents}

1. $1.5 \mathrm{ml}$ Screw-capped microtube (Watson, catalog number: $139-115-112 \mathrm{C}$ )

2. $1.5 \mathrm{ml}$ microtube (Safe-Lock Tube, Eppendorf, catalog number: 0030120086)

3. Pipette tips (Gilson)

4. Membrane filter unit (Amicon-Ultra, $100 \mathrm{kDa}$, Merck Millipore, catalog number: UFC510096)

5. Reverse-phase HPLC column (COSMOSIL 5C18-MSII, $4.6 \mathrm{~mm} \times 200 \mathrm{~mm}$, Nacalai Tesque)

6. TLC plate (Merck Millipore, catalog number: 1.05554.0001)

7. Plastic wrap

8. Amiloride-tin-precursor (A21a, $1.0 \mathrm{mM}$ in ethanol, Figure $1 \mathrm{~A}$, The synthetic procedures are described in Uno et al., 2019)

9. [125J] Nal (carrier-free, $2,000 \mathrm{Ci} / \mathrm{mmol}$, Perkin-Elmer, catalog number: NEZ033A)

10. Chloramine T (Wako Pure Chemicals, catalog number: 032-02182)

11. Sodium hydrogen sulfite $\left(\mathrm{NaHSO}_{3}\right.$, Wako Pure Chemicals, catalog number: 198-01371)

12. Bovine submitochondrial particles (SMPs)

Notes:

a. SMPs are inside-out vesicles of inner mitochondrial membrane.

b. Mitochondria were isolated from bovine heart as described elsewhere (Smith, 1967).

c. SMPs were prepared on the basis of the previously described protocol (Matsuno-Yagi and Hatefi, 1985) using a sonication medium containing $0.25 \mathrm{M}$ sucrose, $1.0 \mathrm{mM}$ potassium succinate, $1.5 \mathrm{mM} \mathrm{ATP}, 10 \mathrm{mM} \mathrm{MgCl}_{2}, 10 \mathrm{mM} \mathrm{MnCl}_{2}$, and $10 \mathrm{mM} \mathrm{Tris/HCl}(\mathrm{pH} \mathrm{7.4)}$, followed 
by ultracentrifugation. They are stored in a buffer containing $250 \mathrm{mM}$ sucrose and $10 \mathrm{mM}$

Tris- $\mathrm{HCl}\left(\mathrm{pH} \mathrm{7.4)}\right.$ at $-80^{\circ} \mathrm{C}$ until used.

13. NativePAGE ${ }^{\mathrm{TM}}$ Bis-Tris protein gels $(4-16 \%$ precast gel, Thermo Fisher, catalog number: BN1004BOX)

14. NativePAGE ${ }^{\mathrm{TM}}$ Runnning buffer and Cathode buffer additive (Thermo Fisher, catalog numbers: BN2001 and BN2002, respectively)

15. Serva Blue G (CBB G-250, Serva, catalog number: 35050.01)

16. $n$-Dodecyl-D- $\beta$-maltoside (DDM, Dojin, catalog number: D316)

17. Glycerol (Wako Pure Chemicals, catalog number: 075-00616)

18. Ethanol (Wako Pure Chemicals, catalog number: 057-00456)

19. Methanol (Wako Pure Chemicals, catalog number: 137-01823)

20. Acetic acid (Wako Pure Chemicals, catalog number: 017-00251)

21. Sucrose (Wako Pure Chemicals, catalog number: 192-00017)

22. $\mathrm{MgCl}_{2}$ (hexahydrate, Wako Pure Chemicals, catalog number: 135-00165)

23. $\mathrm{NaCl}$ (Wako Pure Chemicals, catalog number: 195-01665)

24. Ponceau $S$ (Nacalai Tesque, catalog number: 28322-72)

25. Tricine (Dojin, catalog number: GB05)

26. SDS (Wako Pure Chemicals, catalog number: 191-07145)

27. Mercaptethanol (Wako Pure Chemicals, catalog number: 137-06862)

28. Tris (Wako Pure Chemicals, catalog number: 011-20095)

29. Acrylamide (Wako Pure Chemicals, catalog number: 011-08015)

30. Bis-acrylamide (Wako Pure Chemicals, catalog number: 134-15081)

31. Urea (Wako Pure Chemicals, catalog number: 219-00175)

32. Silver Stain Kit (Wako Pure Chemicals, catalog number: 291-50301, compatible with MS)

33. Trifluoroacetic acid (TFA)

34. NADH (Oriental Yeast, catalog number: 44320000)

35. Labeling buffer (see Recipes)

36. 4x BN-PAGE sample buffer (see Recipes)

37. Elution buffer (see Recipes)

38. 4x Schägger sample buffer (see Recipes)

39. $10 x$ cathode buffer (see Recipes)

40. 10x anode buffer (see Recipes)

41. AB-3 mix (see Recipes)

42. 3x gel buffer (see Recipes)

43. 1.0 M KPi buffer, pH 7.4 (see Recipes)

44. Gel composition for dSDS-PAGE (see Recipes) 


\section{Equipment}

1. Pippetmann (Gilson)

2. $-80^{\circ} \mathrm{C}$ freezer (PHC, model: MDF-DU300H)

3. HPLC system (Shimazdu, model: LC-10AS)

4. Micro-centrifuge (CHIBITAN, Merck Millipore, model: XX42CF0RT)

5. Y-counter (COBRA ${ }^{\mathrm{TM}}$ II, Packard)

6. Vacuum centrifugal evaporator (EYELA, model: CVE-2200)

7. Bio-imaging analyzer (FLA-5100 or Typhoon FLA-9000, Fuji Film or GE healthcare, respectively)

8. Imaging plate (BAS IP MS 2040E, GE Healthcare)

9. Vortex mixer (AS ONE, model: Trio TM-1N)

10. Heat block (AS ONE, model: MyBL-10)

11. Long wavelength UV lamp (UVP, Black-lay model B-100AP, equipped with a $100 \mathrm{~W}$ bulb, 365 $\mathrm{nm})$

12. Electro-Eluter (Bio-Rad, model: 422)

13. Gel dryer (Bio-Rad, Model583, equipped with HydroTech vacuum pump)

14. Gel electrophoresis apparatus and glass plates (ATTO, AE-6500, 8 × $9 \mathrm{~cm}$ for mini-size gel format)

\section{Software}

1. Image analysis software such as Multi Gauge or Image Quant (Fuji Film or GE Healthcare, respectively)

\section{Procedure}

A. Preparation of photoreactive $\left[{ }^{125} \mid\right]$ amilorides ([$\left.{ }^{125} \mid\right] P R A 5$ as an example)

1. Prepare ethanolic solution of Tin-precursor A21a $(1.0 \mathrm{mM}, 20 \mu \mathrm{l})$ in a screw-capped $1.5 \mathrm{ml}$ microtube.

2. Add [ $\left.{ }^{125}\right] \mathrm{Nal}(1 \mathrm{mCi}, 2,000 \mathrm{Ci} / \mathrm{mmol}, 10 \mu \mathrm{l})$.

Note: $\left[{ }^{1251}\right] \mathrm{Nal}$ should be handled in a draft chamber until the reaction is quenched by $\mathrm{NaHSO}_{3}$.

3. Initiate the reaction by the addition of aqueous chloramine $\mathrm{T}(3.0 \mathrm{mM}$ in $1.0 \mathrm{M} \mathrm{KPi}$ buffer, $\mathrm{pH}$ $7.4,10 \mu \mathrm{l})$.

Note: Aqueous chloramine $T$ solution should be freshly prepared for each experiment.

4. Vortex and spin-down the tube.

5. Incubate the mixture for $10 \mathrm{~min}$ at room temperature.

6. Quench the reaction by the addition of $5 \%(\mathrm{w} / \mathrm{v})$ aqueous sodium hydrogen sulfite $(10 \mu \mathrm{l})$.

7. Inject whole volume of the mixture $(\sim 50 \mu \mathrm{l})$ to the HPLC with a manual injection port (loop volume should be larger than $100 \mu \mathrm{l})$. LC conditions are as follows: 

a. Column: COSMOSIL 5C18-MSII, $4.6 \mathrm{~mm} \times 200 \mathrm{~mm}$ (Nacalai Tesque)
b. Solvent: methanol/0.01\% aqueous TFA (step gradient elution of 1:9, then 9:1).
c. Temperature: $35^{\circ} \mathrm{C}$
d. Flow rate: $0.8 \mathrm{ml} / \mathrm{min}$.

8. Collect fractions every $30 \mathrm{~s}(\sim 400 \mu \mathrm{l})$.

9. Take $3 \mu \mathrm{l}$ of the samples to assess the radioactivity and purity of each fractions by $\mathrm{Y}$-counter (2 $\mu \mathrm{l})$ and radio-TLC $(1 \mu \mathrm{l})$, respectively (see Figure 2 ).

10. Combine the fractions containing [125] PRA5 (frs. 8 and 9 in Figure 2), and concentrate the sample up to $\sim 50 \mu \mathrm{l}$ by a vacuum-centrifugal evaporator.

Note: Do not dry the sample completely.

11. Adjust the concentration of [ $\left.{ }^{125}\right]$ PRA 5 to $1 \mathrm{mCi} / \mathrm{ml}$ by ethanol.

12. Store the sample at $4{ }^{\circ} \mathrm{C}\left(\left[{ }^{125} \mid\right]\right.$ amilorides are stable as ethanolic solutions for at least 2 months).

A

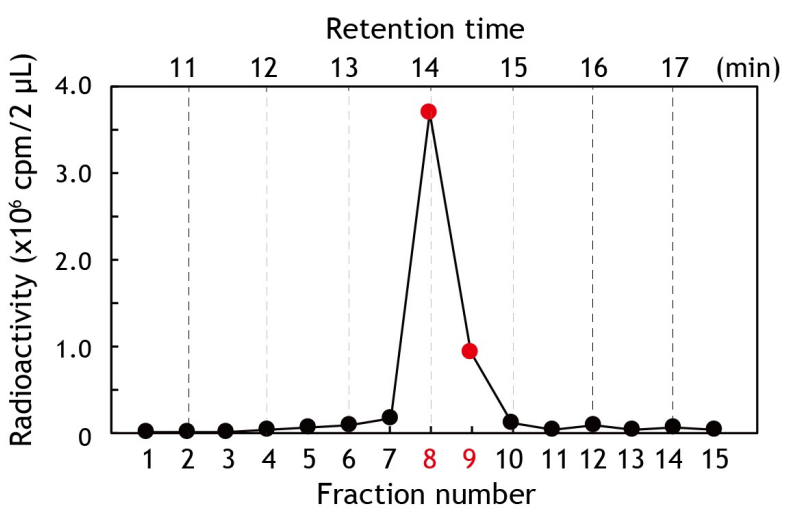

B

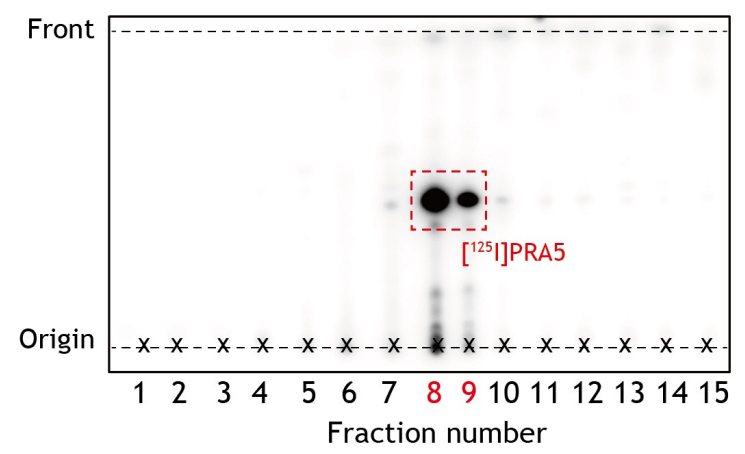

Figure 2. Purification of photoreactive [125]]PRA5 by reverse phase HPLC. The mixture containing crude [125]]PRA5 was applied to a C18 column. The salts were removed by rinsing the column with $10 \%$ methanol/0.01\% aqueous TFA $(0-10 \mathrm{~min})$, then [125]]PRA5 was eluted with an isocratic $90 \%$ methanol $/ 0.01 \%$ aqueous TFA (10-20 min). The elute was fractionated every $30 \mathrm{~s}$, and $2 \mu \mathrm{l}$ aliquot from each fraction was transferred to RIA tube and the radioactivity was measured using $\mathrm{Y}$-counter (retention time; 10-17.5 min). A. Radioactivity distribution in HPLC chromatogram. The radiochemical yield was approximately $70 \%$ from the initial [ $\left.\left.{ }^{125}\right]\right] \mathrm{Nal}$. B. TLC analysis of the collected fractions. The samples $(1 \mu \mathrm{l})$ were analyzed on a TLC plate using $10 \%$ methanol/chloroform as a mobile phase. The plate was exposed on an imaging plate for $1 \mathrm{~h}$ and 
analyzed by Bio-imaging analyzed FLA-5100.

B. Cross-linking of bovine SMPs by [125I]PRA5

1. In a $1.5 \mathrm{ml}$ microtube, add the suspension of bovine SMPs in the labeling buffer $(2.0-4.0 \mathrm{mg} / \mathrm{ml}$, $100-200 \mu \mathrm{l})$.

2. Add [125I]PRA5 at the concentration of $5-10 \mathrm{nM}$.

Note: Ethanol concentration should be below $\sim 3 \%$.

3. Incubate at room temperature for $10 \mathrm{~min}$.

4. Add $50 \mu \mathrm{M} \mathrm{NADH}$, then incubate for $5 \mathrm{~min}$.

5. Irradiate with a long wavelength UV lamp on ice for $10 \mathrm{~min}$ at the distance of $10 \mathrm{~cm}$ from the light source (Figure 3).

6. Quench the cross-linking reaction by adding $10 \%(\mathrm{w} / \mathrm{v})$ DDM to a final concentration $1.0 \%$.

7. Incubate the mixture on ice for $1 \mathrm{~h}$.

8. Add 4x BN-PAGE sample buffer.

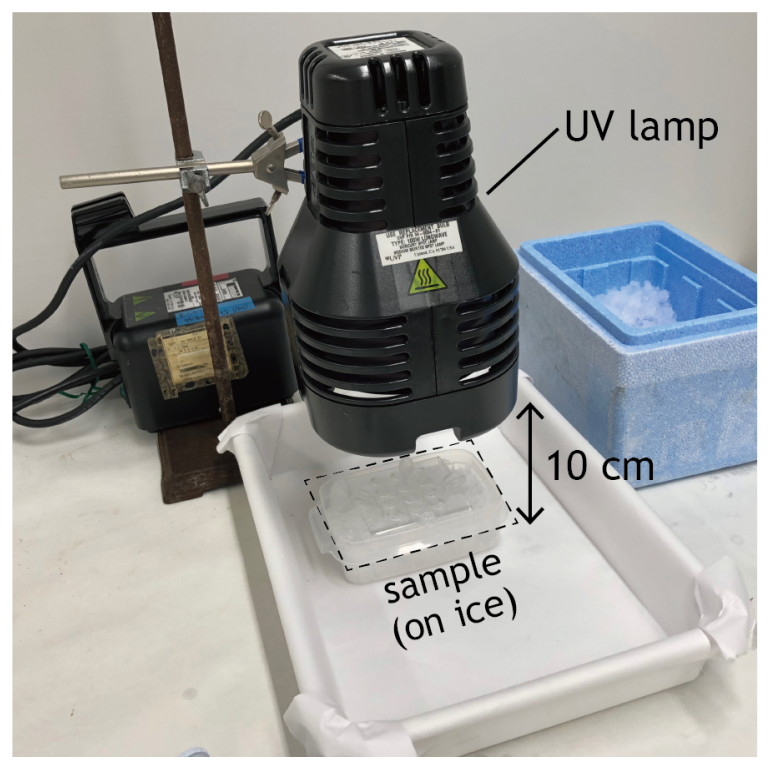

Figure 3. A set-up for photoaffinity labeling of bovine SMPs. The $1.5 \mathrm{ml}$ Eppendorf tubes containing SMPs are placed with open lids on ice. They are UV-irradiated for $10 \mathrm{~min}$ at the distance of approximately $10 \mathrm{~cm}$ from the light source. For efficient labeling, the volume of the sample should be 100-200 $\mu$ l/tube.

C. Identification of the protein labeled by [125I]PRA5

1. Isolation of complex I by Blue Native (BN)-PAGE and electroelution (Schägger, 2006)

a. Add $5 \%$ Serva Blue G (CBB G-250). The CBB/DDM ratio should be adjusted to be $1 / 4$ by weight.

b. Load samples into the $4-16 \%$ BN-precast gel (100-200 $\mu \mathrm{g}$ protein/well).

c. Start electrophoresis (100 V, $15 \mathrm{~mA}$, for $1 \mathrm{~h})$. 
d. Increase the voltage to $200 \mathrm{~V}(15 \mathrm{~mA})$, and continue electrophoresis until the front dye reaches the bottom of the gel.

e. Excise the complex I band with a razor blade.

Note: Do not fix the BN gel. Do not include any unstained (or poorly stained) gel. Excise only the heart of the complex I band.

f. Assemble the Electro-Eluter according to the manufacturer's protocols.

g. Fill the glass tube and the Eluter with elution buffer, and place the gel piece in the tube (4-5 gel pieces/tube).

h. Elute protein at $10 \mathrm{~mA} / \mathrm{glass}$ tube for overnight in a cold room.

Note: If the elution is successful, the gel piece becomes colorless.

i. Collect the eluted protein according to the manufacturer's protocol (We recommend washing the dialysis membrane with $50-100 \mu \mathrm{l}$ of $0.5 \%$ SDS to solubilize the precipitated proteins).

j. Concentrate the collected solution with Amicon-Ultra 0.5 (100 kDa cut-off) to the appropriate volume $(50-100 \mu \mathrm{l})$.

k. Store the sample at $-80^{\circ} \mathrm{C}$ until used.

2. Resolution of complex I subunits by doubled SDS-PAGE (dSDS-PAGE, Rais et al., 2004; Wittig, 2006)

a. Add $4 x$ Schägger sample buffer to the complex I isolated by electroelution.

b. Incubate the mixture at $40{ }^{\circ} \mathrm{C}$ for $1 \mathrm{~h}$.

Note: Do not boil the samples because some hydrophobic subunits in complex I aggregate.

c. Separate complex I proteins on a first dimensional Schägger-type SDS gel (10\% T, 3\% C containing $6.0 \mathrm{M}$ urea with $4 \%$ stacking gel, Table 1$)$ with a voltage of $30 \mathrm{~V}(40 \mathrm{~mA})$.

d. When the samples have completely entered the gel, increase the voltage to $100 \mathrm{~V}$, and continue electrophoresis until the dye front reaches the bottom of the gel.

e. Excise a first dimensional gel strip and incubate it for $30 \mathrm{~min}$ in an acidic buffer containing $100 \mathrm{mM}$ Tris/ $\mathrm{HCl}(\mathrm{pH} 2.0$ ), then fix the strip between two glass plates (see Figures 4A, 4B, and $4 \mathrm{C})$.

f. Pour the second dimensional acrylamide mixture (16\% T, 3\% C, Table 1) and overlay with water (see Figure 4D).

g. After polymerization, push down the first dimensional gel strip and make the two gels stick together (see Figure 4E).

h. Fill the gap with acrylamide mixture $(16 \% \mathrm{~T}, 3 \% \mathrm{C}$, Table 1) containing $150 \mathrm{mM}$ Tris/ $\mathrm{HCl}(\mathrm{pH}$ 7.4) and trace of Serva Blue G (spacer gel, see Figure 4F).

i. Start second dimensional electrophoresis with a voltage of $30 \mathrm{~V}(40 \mathrm{~mA})$.

j. When the samples have completely entered the second dimensional gel, the voltage can be increased to $150 \mathrm{~V}$.

3. Silver stain and autoradiography

a. Fix and stain the gel with silver by an appropriate method (Yan et al., 2000) or by 
commercially available silver stain kit.

b. Scan the silver-stained gel using a conventional flatbed scanner.

c. Before place the gel on the gel drier, equilibrate the gel in a solution containing $3 \%$ glycerol, $40 \%$ methanol, and $10 \%$ acetic acid for $30 \mathrm{~min}$.

d. Dry the gel using gel drier at $65{ }^{\circ} \mathrm{C}$ for $3 \mathrm{~h}$. Temperature should be raised slowly [about $1{ }^{\circ} \mathrm{C} /$ min ("Gradient mode")].

e. When the gel is completely dried, cover the gel with plastic wrap, then expose it onto the imaging plate for 12-24 $\mathrm{h}$.

f. Analyze the migration pattern of radio-labeled proteins by Bio-imaging analyzer, and compare those of silver-stained protein (representative results are shown in Figure 5).

A

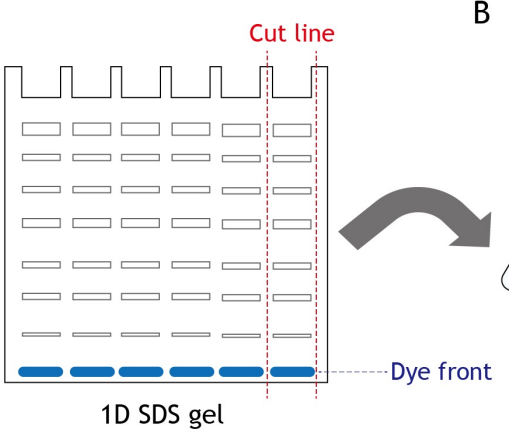

$B$

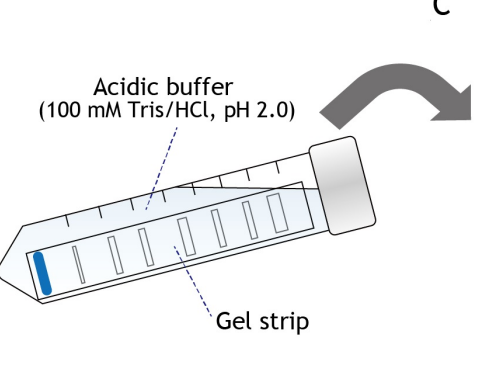

C

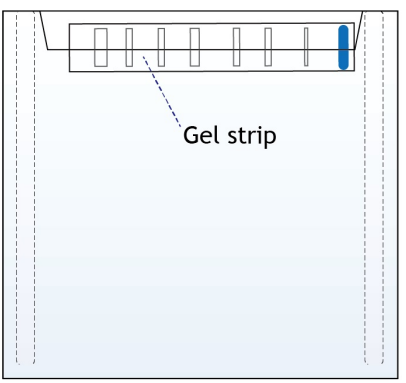

D

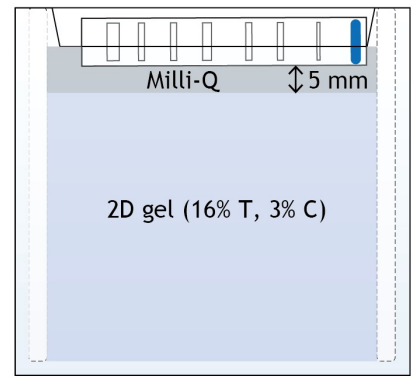

$\mathrm{E}$

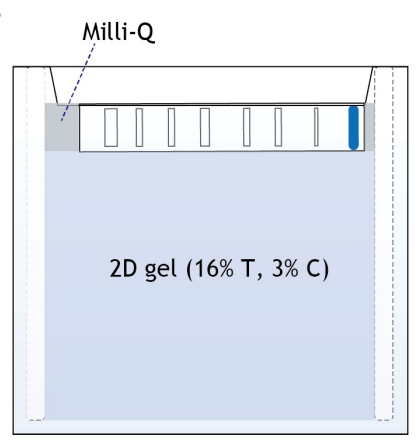

$\mathrm{F}$

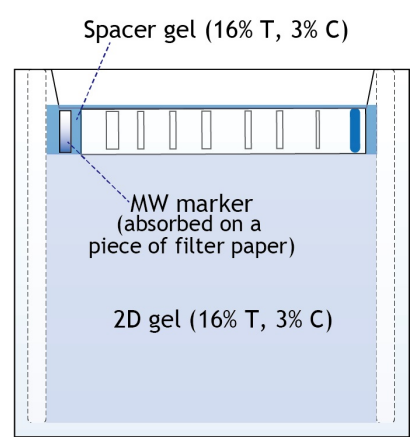

Figure 4. Preparation of the second dimensional gel for dSDS-PAGE. A. Excise the first dimensional gel strip. B. Carefully place the gel strip to a $15 \mathrm{ml}$ falcon tube containing an acidic buffer. Incubate the gel for $30 \mathrm{~min}$ at room temperature. C. Fix the strip between two glass plates. D. Pour the second dimensional acrylamide mixture, and overlay with Milli-Q $\mathrm{H}_{2} \mathrm{O}$. E. After polymerization of the acrylamide gel mixture, push down the gel strip to make the two gels stick together. F. Remove Milli-Q, then fill the gap with a spacer gel. 


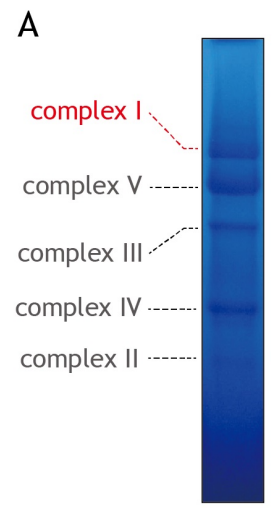

B

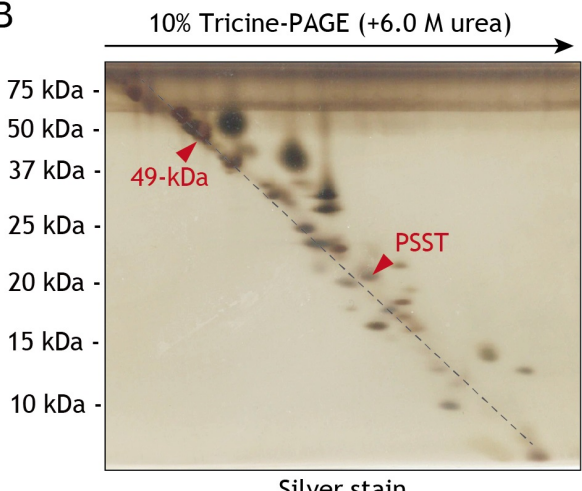

10\% Tricine-PAGE (+6.0 M urea)

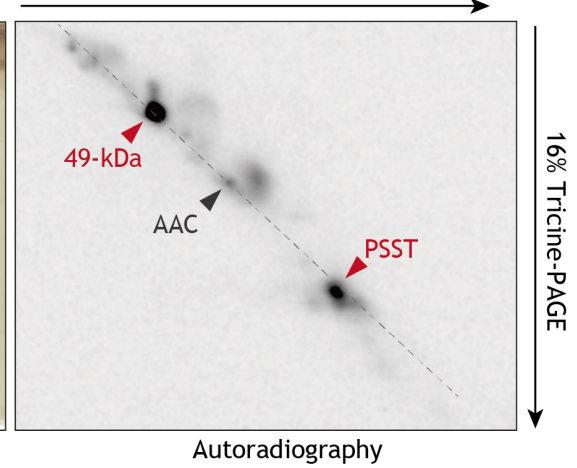

Figure 5. Analysis of the proteins in SMPs labeled by [125]]PRA5. A. Separation of complex I by BN-PAGE. The SMPs labeled by [125|]PRA5 were separated on a $4-16 \%$ BN gel. The complex I band was identified by activity stain by NADH/NBT system, as described elsewhere (Murai et al., 2009; Shiraishi et al., 2012), and subjected to electroelution. Approximately 100 $\mu \mathrm{g}$ of SMPs proteins were loaded into each well. B. Resolution of complex I by dSDS-PAGE. The [125]]PRA5-labeled complex I, purified by BN-PAGE and electroelution, was separated on a first dimensional 10\% Schägger-type Tricine gel (10\% T, 3\% C containing 6.0 M urea), followed by second dimensional separation on a $16 \%$ Schägger-type gel ( $16 \% \mathrm{~T}, 3 \% \mathrm{C})$. The $2 \mathrm{D}$ gel was subjected to silver stain (left) and autoradiography (right). The labeling by [ $\left.{ }^{125}\right]$ PRA5 provided two radioactive spots corresponding to the 49-kDa and PSST subunits, both of which comprise the quinone/inhibitor-binding pocket of complex I (Hirst 2013 and Sazanov 2015). The spots were identified by mass spectrometry and Western blotting (Shiraishi et al., 2012). We note that the weak radioactivity was found in a protein spot of ADP/ATP carrier (AAC), which was copurified with complex I. The gel images are the same as those used in Figure $7 \mathrm{C}$ of the reference (Uno et al., 2019).

\section{Recipes}

1. Labeling buffer (for UV irradiation of bovine SMP)

$250 \mathrm{mM}$ sucrose

$50 \mathrm{mM} \mathrm{KPi} \mathrm{(pH} \mathrm{7.4)}$

$1 \mathrm{mM} \mathrm{MgCl} 2$

2. $4 \times B N-P A G E$ sample buffer

$200 \mathrm{mM}$ Bis-Tris/ $\mathrm{HCl}(\mathrm{pH} 7.2)$

$200 \mathrm{mM} \mathrm{NaCl}$

$40 \%(w / v)$ glycerol

$0.004 \%$ (w/v) Ponceau S

3. Elution buffer (for electroelution of complex I)

$25 \mathrm{mM}$ Tricine

$7.5 \mathrm{mM}$ Bis-Tris $/ \mathrm{HCl}\left(\mathrm{pH} 7.0\right.$ adjusted at $\left.4{ }^{\circ} \mathrm{C}\right)$ 
4. 4x Schägger sample buffer (for Tricine-PAGE)

$150 \mathrm{mM}$ Tris/ $\mathrm{HCl}(\mathrm{pH} 7.0)$

$12 \%(w / v)$ SDS

$30 \%(w / v)$ glycerol

$6 \%(\mathrm{w} / \mathrm{v})$ mercaptoethanol

$0.05 \%(w / v)$ Serva Blue G

5. 10x cathode buffer (for Schägger-type SDS-PAGE)

1.0 M Tris

1.0 M Tricine

$1 \%$ SDS

6. 10x anode buffer (for Schägger-type SDS-PAGE)

1.0 M Tris/ $\mathrm{HCl}(\mathrm{pH} 8.9)$

7. $A B-3$ mix (49.5\% T, $3 \%$ C, for Schägger-type SDS-PAGE)

$48 \%$ acrylamide

$1.5 \%$ bis-acrylamide

8. $3 x$ gel buffer (for Schägger-type SDS-PAGE)

3.0 M Tris/ $\mathrm{HCl}(\mathrm{pH} 8.45)$

$0.3 \%$ SDS

9. $\quad 1.0 \mathrm{M} \mathrm{KPi} \mathrm{buffer,} \mathrm{pH} 7.4$

Dissolve $\mathrm{K}_{2} \mathrm{HPO}_{4}(12.1 \mathrm{~g}, 69.5 \mathrm{mmol})$ and $\mathrm{KH}_{2} \mathrm{PO}_{4}(4.1 \mathrm{~g}, 30.4 \mathrm{mmol})$ in $100 \mathrm{~mL}$ of distilled water.

10. Gel composition for dSDS-PAGE (for Schägger-type SDS-PAGE) (Table 1)

Table 1. Preparation of Schägger-type SDS gels (for two ATTO mini-size gels)

\begin{tabular}{|c|c|c|c|c|}
\hline \multirow[b]{2}{*}{ Reagents } & \multirow{2}{*}{$\begin{array}{c}\text { 4\% stacking } \\
\text { gel }\end{array}$} & \multicolumn{2}{|c|}{ Running gel } & \multirow[b]{2}{*}{$16 \%$ Spacer gel } \\
\hline & & $\begin{array}{l}10 \% \text { (+ Urea) } \\
\text { (first dimension) }\end{array}$ & $\begin{array}{l}16 \% \text { (second } \\
\text { dimension) }\end{array}$ & \\
\hline AB-3 mix. & $0.5 \mathrm{ml}$ & $3.0 \mathrm{ml}$ & $5 \mathrm{ml}$ & $1.0 \mathrm{ml}$ \\
\hline 3x Gel buffer & $1.5 \mathrm{ml}$ & $5.0 \mathrm{ml}$ & $5 \mathrm{ml}$ & - \\
\hline Urea & - & $5.4 \mathrm{~g}$ & - & - \\
\hline Dist. Water & $4.0 \mathrm{ml}$ & $3.0 \mathrm{ml}$ & $5 \mathrm{ml}$ & $1.55 \mathrm{ml}$ \\
\hline $1 \mathrm{M}$ Tris/HCl $(\mathrm{pH} 7.4)$ & - & - & - & $0.45 \mathrm{ml}$ \\
\hline Serva blue G & - & - & - & Trace \\
\hline $10 \%$ APS Sol & $50 \mu \mathrm{l}$ & $80 \mu \mathrm{l}$ & $80 \mu \mathrm{l}$ & $15 \mu \mathrm{l}$ \\
\hline TEMED & $6 \mu \mathrm{l}$ & $10 \mu \mathrm{l}$ & $8 \mu \mathrm{l}$ & $2 \mu \mathrm{l}$ \\
\hline Total volume & $6.0 \mathrm{ml}$ & $15 \mathrm{ml}$ & $15 \mathrm{ml}$ & $3.0 \mathrm{ml}$ \\
\hline
\end{tabular}




\section{Acknowledgments}

This protocol was adapted from Uno et al. (2019). This study was supported by JSPS KAKENHI (Grant Numbers JP26292060 and JP18H02147 to H.M., Grant Number JP18K05458 to M.M.). The experiments involving radioisotope techniques were performed at the Radioisotope Research Center, Kyoto University.

\section{Competing interests}

The authors declare that they have no conflicts of interest with the contents of this article.

\section{References}

1. Hatanaka, Y. and Sadakane, Y. (2002). Photoaffinity labeling in drug discovery and developments: chemical gateway for entering proteomic frontier. Curr Top Med Chem 2(3): 271288.

2. Hirst, J. (2013). Mitochondrial complex I. Annu Rev Biochem 82: 551-575.

3. Matsuno-Yagi, A. and Hatefi, Y. (1985). Studies on the mechanism of oxidative phosphorylation. Catalytic site cooperativity in ATP synthesis. J Biol Chem 260(27): 11424-11427.

4. Murai, M., Sekiguchi, K., Nishioka, T. and Miyoshi, H. (2009). Characterization of the inhibitor binding site in mitochondrial NADH-ubiquinone oxidoreductase by photoaffinity labeling using a quinazoline-type inhibitor. Biochemistry 48(4): 688-698.

5. Murai, M., Murakami, S., Ito, T. and Miyoshi, H. (2015). Amilorides bind to the quinone binding pocket of bovine mitochondrial complex I. Biochemistry 54(17): 2739-2746.

6. Rais, I., Karas, M. and Schägger, H. (2004). Two-dimensional electrophoresis for the isolation of integral membrane proteins and mass spectrometric identification. Proteomics 4(9): 25672571.

7. Sazanov, L. A. (2015). A giant molecular proton pump: structure and mechanism of respiratory complex I. Nat Rev Mol Cell Biol 16(6): 375-388.

8. Schägger, H. (2006). Tricine-SDS-PAGE. Nat Protoc 1(1): 16-22.

9. Shiraishi, Y., Murai, M., Sakiyama, N., Ifuku, K. and Miyoshi, H. (2012). Fenpyroximate binds to the interface between PSST and $49 \mathrm{kDa}$ subunits in mitochondrial NADH-ubiquinone oxidoreductase. Biochemistry 51(9): 1953-1963.

10. Smith, A. L. (1967). Mitochondria : Slaughterhouse Material, Small-Scale. Methods Enzymol 10: 81-86.

11. Uno, S., Kimura, H., Murai, M. and Miyoshi, H. (2019). Exploring the quinone/inhibitor-binding pocket in mitochondrial respiratory complex I by chemical biology approaches. J Biol Chem 294(2): 679-696.

12. Wang, Q., Chan, T. R., Hilgraf, R., Fokin, V. V., Sharpless, K. B. and Finn, M. G. (2003). 
Bioconjugation by copper(I)-catalyzed azide-alkyne [3+2] cycloaddition. J Am Chem Soc 125(11): 3192-3193.

13. Wirth, C., Brandt, U., Hunte, C. and Zickermann, V. (2016). Structure and function of mitochondrial complex I. Biochim Biophys Acta 1857(7): 902-914.

14. Wittig, I., Braun, H. P. and Schägger, H. (2006). Blue native PAGE. Nat Protoc 1(1): 418-428.

15. Yan, J. X., Wait, R., Berkelman, T., Harry, R. A., Westbrook, J. A., Wheeler, C. H. and Dunn, M. J. (2000). A modified silver staining protocol for visualization of proteins compatible with matrixassisted laser desorption/ionization and electrospray ionization-mass spectrometry. Electrophoresis, 21(17): 3666-3672. 